\title{
Factors affecting cardiovascular risk in patients with type 2 diabetes mellitus; a clinic based study
}

Rathnayake R M U K ${ }^{1}$, Rathnayake T L ${ }^{2}$, Rathnayake R M J B ${ }^{3}$, Abewardena T T L ${ }^{2}$, SenevirathneEpa S ${ }^{4}$

${ }^{1}$ District General Hospital Matara, ${ }^{2}$ Primary Medical Care Unit, Devinuwara ${ }^{3}$ Faculty of Medicine, Ruhuna ${ }^{4}$ Matara Nurisng Home, Matara

Copyright: This is an open-access article distributed under the terms of the Creative Commons Attribution License, which permits unrestricted use, distribution, and reproduction in any medium, provided the original author and source are credited (CC BY 4.0)

Correspondence email: urathke@gmail.com

\section{Introduction}

World health organization estimated that 347 million people worldwide were having diabetes mellitus in 2013. The aging population and increasing prevalence of obesity and sedentary life habits among people increase the prevalence of diabetes (1). Prevalence of diabetes mellitus globally was 8.3\% in 2011 and for the South East Asia it was 8.3\% (2). Prevalence of diabetes in Sri Lanka was $10.3 \%$ in 2008, which has steeply increased from values of $2.01 \%$ in 1988 . Sri Lanka diabetes and cardiovascular study (SLDCS) which was done in 2008 has revealed a diabetes female prevalence of $10.9 \%$ amongst females, compared to $9.8 \%$ in males (3).Among the Sri Lankan urban population the prevalence was $16.4 \%$ compared to the rural population which was $11.5 \%$ (3). Prevalence of diabetes mellitus in Southern province of Sri Lanka was $12.2 \%$ (4). Hospital admissions due to diabetes mellitus have increased from $86 / 100.000$ to $226 / 100,000$ over the last two decades $(5,6)$.

This study was conducted in Devinuwara which is a semi urban area in Matara district along the southern coast of Sri Lanka. Majority of people are engaged in the fishing industry. Devinuwara primary medical care unit (PMCU) caters to a population of $8000-10,000$. Our study population was selected from the diabetic patients who visited the medical clinic. Diabetic patients are more prone to develop cardiovascular diseases due to prevalence of risk factors which should be assessed at different stages to minimize complications. Risk of mortality from coronary heart disease and ischemic strokes is raised two to four folds in patients with type 2 diabetes (7). Number of studies have been conducted to assess the cardiovascular disease risk among normal people and selected people in different locations in Sri Lanka. Studies or audits on cardiovascular risk factors among type 2 diabetes mellitus patients who are followed up in the clinics were limited. Thus it is important to ascertain the risk factors for cardiovascular disease among patients with type 2 diabetes mellitus and to assess the risk reduction by interventions in local settings. Further, it will help to minimize the complications of diabetes and persuade life style changes of the affected patient.

\section{Methodology}

This was a descriptive cross sectional study. Convenient sampling method was used to select patients attending the medical clinic with type 2 diabetes mellitus. Patients with type I diabetes mellitus, mentally unfit patients, patients unable to or unwilling to give consent, patients with missing data, and patients with gestational diabetes were excluded from this study. Study was carried out during a period of one year starting from 25th November 2014. An interviewer administered questionnaire was used to collect relevant data. Procedure of the study and benefits to the patient were explained verbally and using a written information sheet. Risk factors assessed were age, menopausal state, and family history of cardiovascular disease (CVD), smoking, alcohol consumption, obesity, physical activity, hypertension, peripheral vascular disease, hyperglycemia, dyslipidemia, and microalbuminuria.

A questionnaire was formulated using World health organization (WHO) non-communicable disease (NCD) risk factor surveillance (STEPS) instrument for NCD risk factor screening. Initial part of the questionnaire included the questions regarding general information of the patient, tobacco use and alcohol consumption. International physical activity questionnaire short version (IPAQ) was used to assess the level of physical activity of the patient (8). Physical activities were categorized into two groups: vigorous and moderate. IPAQ has been validated in Sri Lanka. Sedentary behaviour refers to any walking activity characterized by energy expenditure $\leq 1.5$ metabolic equivalents and a sitting or reclining posture. Resting for more than 52 hours per week was considered as highly 
sedentary, between 34 to 51 hours per week was considered as moderately sedentary and less than 33 hours per week was considered as not sedentary $(8,9)$.

At the time of clinical assessment, a sicca weighing scale was used for weighing the patient without shoes to the nearest $500 \mathrm{~g}$. The height was measured using a stadiometer to the nearest $0.5 \mathrm{~cm}$ with the participant standing upright with the heel, buttock and upper back in the same vertical line. Body

artery on foot. Readings of blood pressures were recorded before and after antihypertensive treatment. Values of the lipid profile were recorded before and after the treatment for dyslipidaemia. Readings of blood pressure and lipid profile values prior to starting treatment were obtained from the patients' record books. Glycosylated haemoglobin (HbA1c) and microalbuminuria were measured at the time of clinical assessment. Ethical approval for this study was granted by the National Institute of health sciences at Kalutara on $15^{\text {th }}$ October 2014 under the reference number NIHS/ERC/14/09/R.

\section{Results}

Out of the total 136 patients in this study, majority were females -112 (82.35\%), and males were 24 (17.64\%). Amongst the female patients $82.14 \%$ (92) were in mass index (BMI) was calculated by dividing weight in kilograms by the square of the height in meters. Waist circumference was measured using a non-stretchable measuring tape. Measurement was taken at a point midway between the lowest rib and iliac crest. Cut off point was taken as $80 \mathrm{~cm}$ (32 inches) for females and $90 \mathrm{~cm}$ (36inches) for males, according to cut-off values recommended for Asians by the international diabetes federation (10). Peripheral pulse was detected by palpation of dorsalis pedis

menopausal state. Age group of this sample varied from 30 to 90 years $($ mean $=61, \mathrm{SD} \pm 10.6)$

Family history revealed that sixty four (47.05\%) had history of cardiovascular disease in the family and $72(52.94 \%)$ had no cardiovascular disease in the family. Duration of the illness was divided in to three categories. Period less than five years was found in $78(57 \%)$ patients, between 6 to 10 years in $41(30 \%)$ patients and more than 10 years in $17(12.4$ $\% \%$ p patients.

None of the female patients consumed alcohol or smoked cigarettes. However, out of the 24 male patients, 12 (50\%) were smokers and $12(50 \%)$ were consuming alcohol. Data related to exercise and resting time was collected according to IPAQ (short version) (8). It is shown in table 2.

Table 1: Age group distribution in number and percentages

Age group in years
Age distribution in number and percentage

\begin{tabular}{l|l}
$21-30$ & $2(1.47 \%)$ \\
$31-40$ & $1(0.74)$ \\
$41-50$ & $20(14.7 \%)$ \\
$51-60$ & $38(27.94 \%)$ \\
$61-70$ & $54(39.7 \%)$ \\
$71-80$ & $14(10.29 \%)$ \\
$>80$ & $7(5.14 \%)$ \\
& 136
\end{tabular}




\begin{tabular}{|c|c|c|c|c|c|}
\hline \multicolumn{4}{|c|}{ Type of exercise } & \multicolumn{2}{|c|}{ Type of resting period } \\
\hline & Vigorous exercise & Moderate exercise & & Sitting time & \\
\hline Minutes per week & Number (\%) & Minutes per week & $\begin{array}{l}\text { Number } \\
(\%)\end{array}$ & Hours per week & Number (\%) \\
\hline$<75$ & $49(36.02)$ & $<150$ & $71(52.21)$ & $<33$ & $115(84.55)$ \\
\hline$>75$ & $51(37.5)$ & $>150$ & $39(28.67)$ & $34-51$ & $20(14.70)$ \\
\hline Zero & $36(26.47)$ & Zero & $26(9.11)$ & $>52$ & $1(0.73)$ \\
\hline Total & 136 & & 136 & & 136 \\
\hline
\end{tabular}

Table 3: Blood pressure at the initial stage of disease and after antihypertensive treatment to appropriate patients and percentages

\begin{tabular}{rl|ll} 
Blood pressure range in mmHg & \multicolumn{2}{c}{ Before treatment } & After treatment \\
Number $(\%)$ & Number $(\%)$ \\
\hline $131 / 81-140 / 90$ & $23(17)$ & $116(85.29)$ \\
$>141 / 91$ & $68(50)$ & $14(10.29)$ \\
Total & 136 & $6(4.41)$ \\
& & 136
\end{tabular}

When the Body Mass Index was analyzed 76 (55.88\%) had BMI above $25 \mathrm{~kg} / \mathrm{m}^{2}$ and were obese (24). Twenty three $(16.91 \%)$ had BMI between $23-24.9 \mathrm{~kg} / \mathrm{m}^{2}$ and were overweight. Twenty seven (19.85\%) had BMI between 18.5 $-22.9 \mathrm{~kg} / \mathrm{m}^{2}$ and were in the normal range and $10(7.36 \%)$ were under weight $(<18.4)$. Waist circumference of the study sample was categorized according to cut off points. Out of 24 males $14(10.29 \%)$ had waist circumference below $90 \mathrm{~cm}$ while $10(7.3 \%)$ had above $90 \mathrm{~cm}$. Among the female only 7 $(5.14 \%)$ had less than $80 \mathrm{~cm}$ waist circumference while $105(77.2 \%)$ had more than $80 \mathrm{~cm}$. 
Forty five patients had normal blood pressure and 91(67\%) had elevated blood pressure. Antihypertensive therapy helped to reduce the blood pressure to normal in $71(52 \%)$ of the patients while $20(14.7 \%)$ had elevated blood pressure even after therapy. This study sample showed a mean value of systolic blood pressure $142 \mathrm{mmHg}$ (SD $\pm 17,139$ $145 \mathrm{mmHg}$ ) at the initial stage of attending the clinic and after starting antihypertensive drugs mean value was changed to $127 \mathrm{mmHg}$ ( $\mathrm{SD} \pm 10,125-128 \mathrm{mmHg}, \mathrm{P}=0.0001)$.

Mean value of total cholesterol was $224 \mathrm{mg} / \mathrm{dl}(\mathrm{SD} \pm 32$, 218$229 \mathrm{mg} / \mathrm{dl}$ ) before treatment and this was reduced to statistically significant mean value of $168 \mathrm{mg} / \mathrm{dl}$ $(\mathrm{SD} \pm 31,162-173 \mathrm{mg} / \mathrm{dl}, \mathrm{p}=0.001)$. Mean value of the low density lipoprotein was $147 \mathrm{mg} / \mathrm{dl}$ (SD $\pm 31,141-152 \mathrm{mg} / \mathrm{dl}$ ) at the initial state and it was reduced significantly to mean value of $101 \mathrm{mg} / \mathrm{dl}(\mathrm{SD} \pm 21,97-104 \mathrm{mg} / \mathrm{dl}, \mathrm{p}=0.001)$ with the lipid lowering drugs. Mean value of high density lipoprotein was $42 \mathrm{mg} / \mathrm{dl}(\mathrm{SD} \pm$ 6.7, 41-43mg/dl) before lipid lowering therapy and it was raised significantly to a mean value of $44 \mathrm{mg} / \mathrm{dl}$ (SD $\pm 3.6,43-44 \mathrm{mg} / \mathrm{dl}$ $\mathrm{p}=0.001)$ after lipid lowering therapy. However, correlational studies of HDL did not show any association between vigorous, moderate or mild exercise.

When the HbA1c was analyzed, 59 (43.38\%) had HbA1c less than $6 \%$ and 71 (52.21\%) had HbA1c between $6-8 \%$. Six people $(4.41 \%)$ had more than $8 \%$. Measurements of albuminuria level of the study sample showed less than $30 \mathrm{mg} / \mathrm{dl}$ in $9(6.7 \%)$ patients, between $31-299 \mathrm{mg} / \mathrm{dl}$ in 103 $(70.7 \%)$ patients and more than $300 \mathrm{mg} / \mathrm{dl}$ in $24(17.6 \%)$ patients. Peripheral pulse of the dorsalis pedis was palpable in $123(90.44 \%)$ and was not felt in 13(9.55\%).

\section{Table 4: Measurement of Lipid levels}

Type of lipid Blood levels Number before treatment $\quad$ Number after treatment
with lipid lowering drugs

\section{Discussion}

This study has revealed cardiovascular risk factors as follows: hypertension in $67 \%$, dyslipidemia in $80 \%$, smoking in $8 \%$, consumption of alcohol in $8 \%$, over weight in $17 \%$, obesity in $56 \%$ and family history of cardiovascular disease in $47 \%$. A substantial number of patients had benefitted by anti-hypertensive drugs and lipid lowering drugs.

A similar study which was done in North Catalonia in 2009, reported a prevalence rate of risk factors among type 2 diabetes patients as follows: hypertension in $74.5 \%$, dyslipidemia in $77.7 \%$, smoking in $14.9 \%$, obesity in $44.9 \%$ and family history of cardiovascular disease in $38.4 \%$ (11). Compared to this study our population indicates higher percentage of obesity and family history of cardiovascular disease (CVD).

$\begin{array}{ll}27(19.85 \%) & 120(88.23 \%) \\ 109(80.14 \%) & 16(11.76 \%) \\ 9(6.61 \%) & 66(48.52 \%) \\ 66(48.52 \%) & 69(50.73 \%) \\ 61(44.85 \%) & 1(0.73 \%) \\ 121(88.97 \%) & 136(100 \%) \\ 15(11.02 \%) & 0\end{array}$

This study sample was based on diabetic patients who pursued to obtain treatment from PMCU, Devinuwara and had a majority of females and minority of males. This may not represent the true gender variation of diabetes in the local population. Employment could be one of the main reasons which may have restricted people, mostly males, attending government hospital clinic held during working hours. In addition, overcrowding of the clinics and certain delays may have contributed for not seeking care from these clinics. Out of the females, majority were in their menopause. It has been found that females experience myocardial infarction later than men due to their protective effect of oestrogen $(12,13)$. State of menopause has made the females of the study sample at high risk for cardiovascular disease. The incidence of myocardial infarction is higher in men than females in general population. In diabetes the incidence ratio is narrower (14). 
Family history of CVD was considered as an independent risk factor (15). In this sample half of the population had family history of CVD. A study has compared incidence of CVD in diabetes patient with family history of CVD and without, and has shown 50\% higher incidence with first degree relatives who had CVD (16). Furthermore, it has shown $14.3 \%$ incidence of CVD among postmenopausal women.

A study conducted in Sri Lanka has found that the prevalence of diabetes was highest in the age group of 55 to 64 years (3). But in this study, majority belonged to the age group of 61 to 70 years. This slight deviation could be due to the gender variation in the sample. Younger age of onset for diabetes and duration of the illness for more than 10 years are considered to be high risk for CVD according to the guideline issued by the American Heart association and American College of Cardiology (AHA/ACC). They further indicate that age below 40 years with shorter duration of illness have less CVD risk (17). In this study, majority belonged to the onset of diabetes less than 5 years category.

Out of the minority of males, twelve $(50 \%)$ had a history of smoking. WHO-Sri Lanka NCD country profile 2011 has recorded a prevalence of smoking among males as $21.4 \%$ (18). Studies have revealed that the smoking increases the risk of heart disease in diabetic patients (19). Prevalence of smoking among males in this sample was much higher, exposing them to the risk of cardiovascular disease. Twelve $(50 \%)$ out of the males in this study had given a history of alcohol consumption. As alcohol consumption alone is a risk factor for cardiovascular disease (20), our study sample male population is at high risk of cardiovascular disease.

When vigorous exercise was considered, only $37 \%$ had achieved the recommended level of more than 75 minutes of vigorous exercise per week. Twenty eight percent of the study group had shown engaging in moderate exercise up to the recommended level which is 150 minutes per week. Eighty percent of the study population had a sitting time less than 33 hours per week which is the recommended level. This may reduce their cardiovascular risk. It has been found that an ambulatory movement every 60 minutes of the day can reduce the risk of premature mortality of all causes by $13 \%$ in adults with diabetes (21).

In this study population majority was either obese or overweight. It has been found that BMI was an independent risk factor for cardiovascular disease and risk is increased by $13 \%$ for 5 unit increase of BMI (22). Further, similar proportion had shown higher waist circumference among females and males. Inappropriate dietetic habits, lack of knowledge, own social values and ignorance may have contributed to the diabetic status.
Blood pressure was more than $141 / 91 \mathrm{~mm} \mathrm{Hg}$ in $50 \%$ of the study sample before starting antihypertensive treatment. After antihypertensive treatment, $85 \%$ of the people had blood pressure below 130/80 mm Hg. A meta-analysis which was done in 2015 revealed lowering of blood pressure by $10 \mathrm{mmHg}$ was significantly lowered the cardiovascular events (23). American Diabetes association (ADA) recommends a goal of systolic pressure of $140 \mathrm{mmHg}$ and diastolic pressure of $90 \mathrm{mmHg}$ for treating diabetics with hypertension (24). This is an achievable target in a clinic.

In $80 \%$ of the study sample, total cholesterol was more than $200 \mathrm{mg} / \mathrm{dl}$ initially before starting lipid lowering therapy. $93 \%$ had LDL cholesterol more than $100 \mathrm{mg} / \mathrm{dl}$, indicating high risk for cardiovascular disease. With lipid lowering therapy $88 \%$ had total cholesterol less than $200 \mathrm{mg} / \mathrm{dl}$. But reduction of LDL cholesterol level below $100 \mathrm{mg} / \mathrm{dl}$, which is the recommended level, was achieved only by $48 \%$ of the study population. The 2013 AHA/ACC guidelines suggest adjusting the statins according to the LDL levels and ability of the patient's tolerance (25). Lipid lowering therapy helped to reduce the risk level of cardiovascular disease in this study group. When HDL cholesterol level is considered, only $11 \%$ had HDL cholesterol less than $35 \mathrm{mg} / \mathrm{dl}$ initially. After lipid lowering therapy $100 \%$ of the study sample had achieved HDL cholesterol level above $35 \mathrm{mg} / \mathrm{dl}$.

HbA1c level is the indicator of glycemic control. A Taiwan study conducted in year 2002 revealed that elevated HbA1c significantly associated with cardiovascular disease risk (26).In this study population, only $5 \%$ had $\mathrm{HbA} 1 \mathrm{c}$ above $8 \%$ and the majority had a good glycaemic control.

In this study sample, $16 \%$ had urine microalbumin more than $300 \mathrm{mg} / \mathrm{l}$. Several studies document an almost linear association between the level of microalbuminuria and risk of cardiovascular event (27). This study sample shows low risk in this aspect.

This study has few limitations. Female preponderance of the sample is a limitation but it signifies the pattern of treatment seeking behaviour in this area. Accelerometer and inclinometers are not used to measure the sedentary hours that was assessed during the interview process. Nonuse of Doppler ultrasonic equipment to assess the peripheral pulse is a limiting factor in our study.

\section{Conclusion}

Though the medication modifiable CVD risk factors like hyperglycaemia, hypertension, and dyslipidaemia have been reduced significantly, behavioural risk factors like alcoholism, smoking and obesity remained to be high among diabetic patient. Analysis of individual dietary pattern and annual risk factor assessment could help reduce the cardiovascular disease risk among diabetic patients. 
1. Diabetes fact sheet WHO reviewed in Oct 2013. https://www.who.int/news-room/fact-sheets/detail/diabetes

2. Ramachandran A, Ma RCW, Snehalatha C: Diabetes in Asia. Lancet 2010, 30: 408-18. 375

3.Katulanda P, Constantine GR, Mahesh JG, Sheriff R, Seneviratne RD, Wijeratne S, Wijesuriya M, McCarthy MI, Adler AI, Matthews DR. Prevalence and projections of diabetes and pre-diabetes in adults in Sri Lanka--Sri Lanka Diabetes, Cardiovascular Study (SLDCS). Diabetic Medicine 2008 Sep; 25(9):1062-9. doi: 10.1111/j.1464-5491.2008.02523.x.

4. Katulanda, P, Rathnapala D, Sheriff R and Matthews D, 2012. Province and ethnic specific prevalence of diabetes among Sri Lankan adults. Sri Lanka Journal of Diabetes Endocrinology and Metabolism, 1(1), pp.2-7. DOI: http://doi.org/10.4038/sjdem.v1i1.4180

5. The National policy and strategic framework for prevention and control of chronic NCD Sri Lanka 2009, Ministry of health. http://www.health.gov.lk/en/publication/Act/NCDPolicy-English.pdf

6. Annual health bulletin, Ministry of Health and Indigenous Medicine, Sri Lanka. 2013:186 http://www.health.gov.lk/en/publication/AHB2013/AHB2013.pdf

7. C, Sarwar N, Gao P, Seshasai SR, Gobin R, Kaptoge S, et al. Diabetes mellitus, fasting blood glucose concentration, and risk of vascular disease: a collaborative meta-analysis of 102 prospective studies. Lancet 2010; 375(9733):2215-22

8. International physical activity questionnaire. 2002:1, http://www.sdp.univ.fvg.it/sites/default/files/IPAQ_English_selfadmin_long.pdf

9. Owen N, Sparling P B, Healy G N, Dunstan D W, Matthews C E, Sedentary Behavior: Emerging Evidence for a New Health Risk. Mayo Clinic Proc 2010 Dec; 85(12): 1138-1141. doi: 10.4065/mcp.2010.0444. PMCID: PMC2996155

10. Sone H, Tanaka S, Ohashi Y, Yamada N. Cut Points of Waist Circumference. Diabetes Care 2006 May; 29(5): 1189-1189. https://doi.org/10.2337/dc06-0329

11. Jurado J , Ybarra J, Solanas P, Caula J, Gich I, Pou J M,June Romeo . Prevalence of cardiovascular disease and risk factors in a type 2 diabetic population of the North Catalonia diabetes study. Journal of the American Association of Nurse Practitioners 2009; https://doi.org/10.1111/j.1745-7599.2008.00377.

12. Rossi R, Grimaldi T, Origliani G, Fantini G, Coppi F, Modena M G. Menopause and cardiovascular risk, Pathophysiol Haemost Thromb 2002;32:325-328. https://doi.org/10.1159/000073591

13. Huxley R, Barzi F, Woodward M. Excess risk of fatal coronary heart disease associated with diabetes in men and women: metaanalysis of 37 prospective cohort studies. BMJ 2006; 332(7533):73-8.

14.Booth GL, Kapral MK, Fung K, Tu JV. Relation between age and cardiovascular disease in men and women with diabetes compared with non-diabetic people: a population-based retrospective cohort study. Lancet 2006; 368(9529):29-36.

15. Yeboah J, McClelland RL, Polonsky TS, Burke GL, Sibley CT, O’Leary D, et al. Comparison of novel risk markers for improvement in cardiovascular risk assessment in intermediate-risk individuals. JAMA 2012; 308(8):788-95.

16. Li R, O’Sullivan MJ, Robinson J, Safford MM, Curb D, Johnson KC. Family history of myocardial infarction predicts incident coronary heart disease in postmenopausal women with diabetes: the Women's Health Initiative Observational Study. Diabetes Metab Res Rev 2009; 25(8):725-32.

17. Stone NJ, Robinson J, Lichtenstein AH, Merz CN, Blum CB, Eckel RH, et al. 2013 ACC/AHA guideline on the treatment of blood cholesterol to reduce atherosclerotic cardiovascular risk in adults: a report of the American College of Cardiology/American Heart Association Task Force on Practice Guidelines. Circulation 2013; 129:1-45.

18. Uditha Bulugahapitiya, Managing cardiovascular risk in type 2 diabetes, Sri Lanka journal of Diabetes, endocrinology and metabolism, editorial 2012;2:1-2 
19.Qin R, Chen T, Lou Q, Yu D. Excess risk of mortality and cardiovascular events associated with smoking among patients with diabetes: meta-analysis of observational prospective studies. International Journal Cardiology 2013; 167(2):342-50.

20. Polsky S, Akturk HK. Alcohol Consumption, Diabetes Risk, and Cardiovascular Disease Within Diabetes. Current Diabetes Reports .2017 Nov 4; 17(1 2):136. doi: 10.1007/s11892-017-0950-8

21. Loprinzi PD, Sng E. The effects of objectively measured sedentary behavior on all-cause mortality in a national sample of adults with diabetes. Preventive Medicine 2016 May; 86 :55-7. doi: 10.1016/j.ypmed.2016.01.023. Epub 2016 Feb 3.

22. Eeg-Olofsson K, Cederholm, J, Nilsson P M et al. Risk of cardiovascular disease and mortality in overweight and obese patients with type 2 diabetes: an observational study in 13,087 patients. Diabetologia (2009), 52: 65. https://doi.org/10.1007/s00125-008$1190-\mathrm{x}$

23. Emdin CA, Rahimi K, Neal B, Callender T, Perkovic V, Patel A. Blood pressure lowering in type 2 diabetes: a systematic review and meta-analysis. Journal of the American Medical Association 2015; 313(6):603-15.

24. Cardiovascular Disease and Risk Management: Standards of Medical Care in Diabetes-2019. American Diabetes Association. Diabetes Care 2019 Jan; 42(Supplement 1): S103-S123. https://doi.org/10.2337/dc19-S010

25. Stone NJ, Robinson J, Lichtenstein AH, Merz CN, Blum CB, Eckel RH, et al. 2013 ACC/AHA guideline on the treatment of blood cholesterol to reduce atherosclerotic cardiovascular risk in adults: a report of the American College of Cardiology/American Heart Association Task Force on Practice Guidelines. Circulation 2013; 129:1-45.

26. Yun-Yu Chen, Yenn-Jiang Lin, Eric Chong, Pei-Chun Chen, Taz-Fan Chao, Shih-Ann Chen, and Kuo-Liong Chien . The Impact of Diabetes Mellitus and Corresponding HbA1c Levels on the Future Risks of Cardiovascular Disease and Mortality: A Representative Cohort Study in Taiwan. PLoS One 2015; 10(4): e0123116. doi: 10.1371/journal.pone.0123116

27. Afkhami - Ardekari M, Modarresi M, Amirchaghmyhi E, Prevalence of microalbuminurea and its risk factors in type 2 diabetic patients. Indian J Nephro 2008 Jul ; 18(3):112-7 doi: 10. 4103/0971- 4065. 43690 